\title{
Circulation types and extreme temperature changes in Greece
}

\author{
P. Maheras ${ }^{1, *}$, H. Flocas ${ }^{2}$, K. Tolika ${ }^{1}$, Chr. Anagnostopoulou ${ }^{1}$, M. Vafiadis ${ }^{3}$ \\ ${ }^{1}$ Department of Meteorology and Climatology, University of Thessaloniki, Thessaloniki 54124, Greece \\ ${ }^{2}$ Laboratory of Meteorology, Department of Applied Physics, Faculty of Physics, University of Athens, Athens, Greece \\ ${ }^{3}$ Division of Faculty of Technology, University of Thessaloniki, Thessaloniki, Greece
}

\begin{abstract}
We examined changes in extreme temperature over the Greek area in relation to the geopotential thickness field (1000 to $500 \mathrm{hPa}$ ). Daily maximum and minimum temperature series from 20 Greek stations evenly distributed over Greece were used for the period 1958-2000. The atmospheric circulation over the Greek area was classified with the aid of a calendar of daily circulation types based on the geopotential thickness field of 1000 to $500 \mathrm{hPa}$ for the same period using daily NCEP and HadAM3P datasets. There was a general increase in frequency of anticyclonic circulation types and a decrease in frequency of cyclonic types. In addition, there was an overall interannual increase (decrease) in maximum (minimum) extreme temperatures over the Greek area, with spatial and seasonal variations. The investigation of the temperature anomalies corresponding to each circulation type, along with the trends of the former, revealed that the increase in frequency of the anticyclonic types, which form positive anomalies, and their positive trends in the majority of the stations, can explain the upward trend of maximum temperature in summer. In contrast, the trend of decreasing minimum temperatures in the central and SW Greek area cannot only be interpreted by changes in frequency of circulation types. A statistical downscaling model for simulating temperature changes over Greece (both for NCEP and HadAM3P datasets) was developed following a circulation-type approach. This demonstrated high correspondence with the observed extreme temperature values in all seasons, with only slightly lower year-to-year variability.
\end{abstract}

KEY WORDS: Greece · Trend analysis · Extreme temperature - Circulation types · Multiple regression · Downscaling $\cdot$ GCM

\section{INTRODUCTION}

Understanding changes in regional climate variability and frequency of extreme events is very important for assessing the impacts on ecosystems, economy and society. For this reason, the assessment of regional changes in temperature extremes is one of the main subjects of current climatological research (DeGaetano \& Allen 2002, Yan et al. 2002, Domonkos et al. 2003, Ryoo et al. 2004).

Although observed changes in temperature cannot always be explained by changes in large scale atmospheric circulation patterns, investigation of the connection between temperature extremes and large scale circulation is important for understanding temperature variability and for developing circulationbased downscaling methods (Xoplaki et al. 2003). Furthermore, there is a strong connection between extreme temperature and changes in the frequency of Hess-Brezowsky circulation patterns over central Europe (Kysely 2002, Domonkos et al. 2003).

The relationship between surface temperature and large-scale circulation over the eastern Mediterranean, including Greece, was the subject of considerable recent research (Corte-Real et al. 1995, Kutiel \& Maheras 1998, Maheras \& Kutiel 1999, Maheras et al. 1999, Kutiel et al. 2002, Feidas et al. 2004). The overall negative trend of temperature variability over the east- 
ern Mediterranean region during the last decades was related to changes in the distribution of mean sea level pressure (Metaxas et al. 1991, Sahsamanoglou \& Makrogiannis 1992) and $500 \mathrm{hPa}$ thermal advection (Makrogiannis \& Sahsamanoglou 1990). This trend, prominent in the 1970s (Giles \& Flocas 1984, Metaxas et al. 1991, Xoplaki et al. 2003), is associated with an increase in the frequency of northerly winds (Bartzokas \& Metaxas 1991) or with the northerly meridional circulation (Maheras et al. 1999, Feidas et al. 2004), which result from the increasing frequency of anticyclonic continental circulation types (ArseniPapadimitriou et al. 2000). However, local warming trends observed in some specific cases have been related to urban heat island effects (Xoplaki 2002).

The objective of this study was to: (1) examine the spatial and temporal relationship between temperature extremes in the Greek area with regional atmospheric circulation, (2) investigate if the identified trends of maximum and minimum temperatures in the Greek area can be explained partially or wholly by changes in the frequency of the circulation types, (3) identify the best predictor (based on circulation over the Greek region) for extreme temperature in order to construct a downscaling procedure based on a circulation-type statistical model and (4) create plausible future temperature scenarios for Greece, employing skilful General Circulation Model (GCM) simulations along with results from the statistical model.

\section{DATA AND METHODOLOGY}

Daily values of maximum (Tmax) and minimum (Tmin) temperature were used for the period 1958-2000 for 20 stations. The stations are evenly distributed over low altitude parts of the Greek area with only 3 stations (Ioannina, Kozani and Tripoli) at altitude $>400 \mathrm{~m}$ (Fig. 1). The temperature series of the 18 stations were obtained from the official Hellenic Meteorological Service. The time series of Athens and Thessaloniki were obtained from the National Observatory of Athens and from the Department of Meteorology and Climatology, Aristotle University of Thessaloniki, respectively. The homogeneity of these datasets was tested using the Alexandersson test (Alexandersson 1986), and a null hypothesis of inhomogeneity of the series was rejected. The selected reference time series accomplished all the necessary criteria listed by Peterson et al. (1998) (i.e. no changes of instruments or observing practices).

The regional atmospheric circulation over the Greek area was studied with the aid of the existing classification catalogue, referring to the 1000 to $500 \mathrm{hPa}$ thickness field on a daily basis. This classification scheme is automatic, semi-objective and was developed using spatial methods of topology and geometry, according to Maheras et al. (2000b). The scheme employed $43 \mathrm{yr}$ (1958-2000) of NCEP reanalysis gridded datasets (Kalnay et al. 1996) of daily $1000 \mathrm{hPa}$ and $500 \mathrm{~h} \mathrm{~Pa}$ geopotential height, with $2.5^{\circ} \times 2.5^{\circ}$ resolution within the European region of 20 to $65^{\circ} \mathrm{N}$ and $20^{\circ} \mathrm{W}$ to $50^{\circ} \mathrm{E}$ : 8 grid points represent the Greek area.

The simulations of grid point 1000 to $500 \mathrm{hPa}$ thickness field of the Hadley Center atmospheric GCM (HadAM3P) were also considered. The HadAM3P model is similar to the HadAM3H model described in detail by Jones et al. (2001). The resolution of the HadAM3P model is high in order to provide the atmospheric response to the global sea-surface temperature (SST) and sea-ice changes. It also provides a more accurate simulation of regional climate, due to a doubling of resolution compared to previous versions of the model. The model data were interpolated in a common grid of $2.5^{\circ} \times 2.5^{\circ}$ as the NCEP data and were used on a daily basis in order to develop an independent circulation type classification.

More specifically, 14 synoptic types have been distinguished: 6 anticyclonic and 8 cyclonic. The naming of anticyclonic and cyclonic circulation

Fig. 1. Geographical distribution of the stations used in the study 
types refers, respectively, to the location of the positive or negative anomaly centres in relation to Greece (Figs. 2 \& 3, Table 1). Each of the circulation types has a distinct underlying synoptic pattern that produces the expected type and direction flow over Greece (Maheras et al. 2000a,b, 2004). Table 1 summarizes their relative frequency.

In order to investigate the trends of temperature extremes, we used not only mean seasonal maximum and minimum temperature but also 2 indices as follows: (1) the 90th percentile for maximum temperature (hereafter referred to as Tmax90p), (2) the 10th percentile for minimum temperature (hereafter referred to as Tmin10p) (Folland et al. 1999, Jones et al. 1999, Holton et al. 2001, Klein Tank \& Konnen 2003). Seasons were defined as follows: winter (December, January, February), spring (March, April, May), summer (June, July, August) and autumn (September, October, November).
Field anomalies

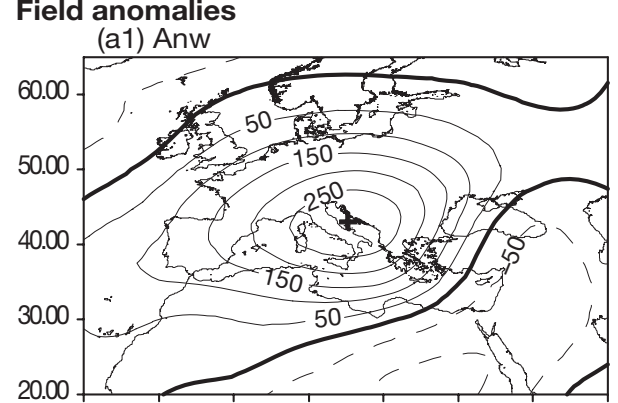

Geopotential heights

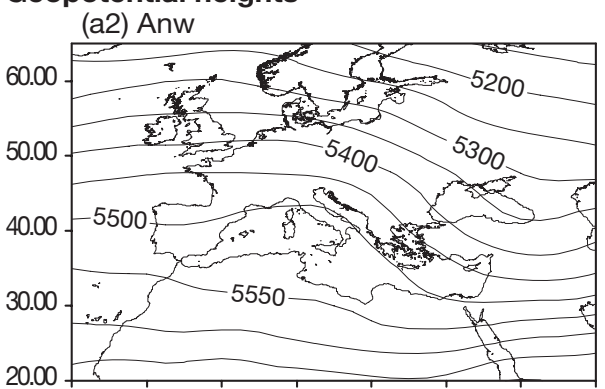

Field anomalies

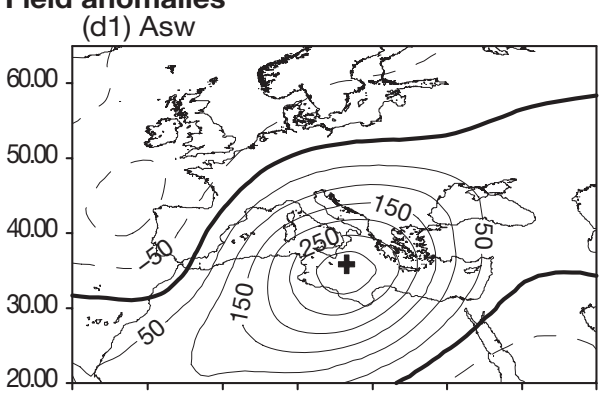

Geopotential heights

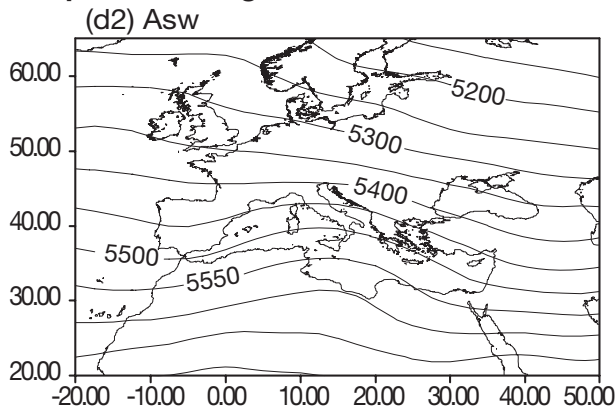

(b1) Ane

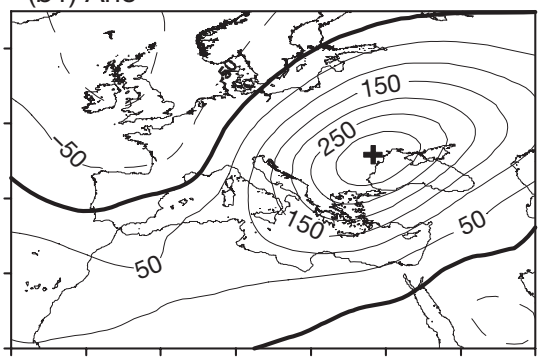

(b2) Ane

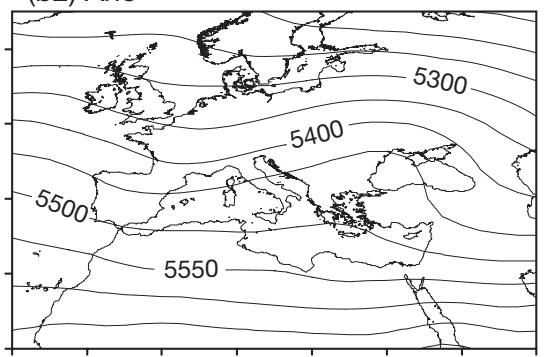

(e1) Ase

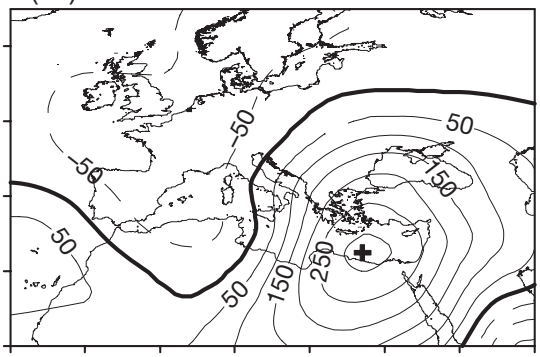

(e2) Ase

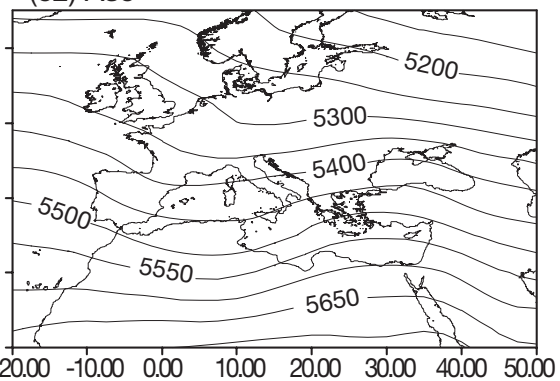

(c1) A

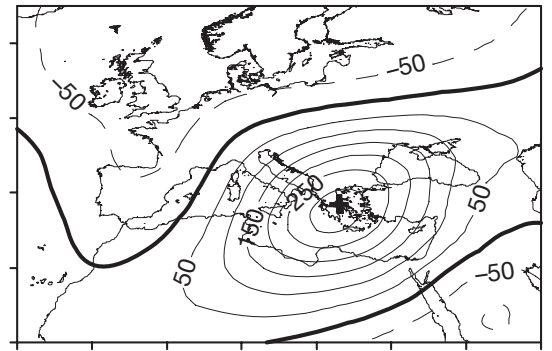

(c2) A

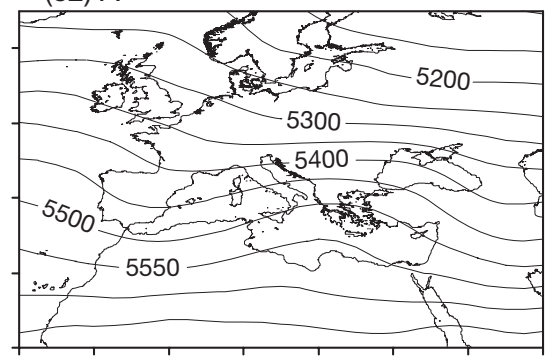

(f1) $\mathrm{Ae}$

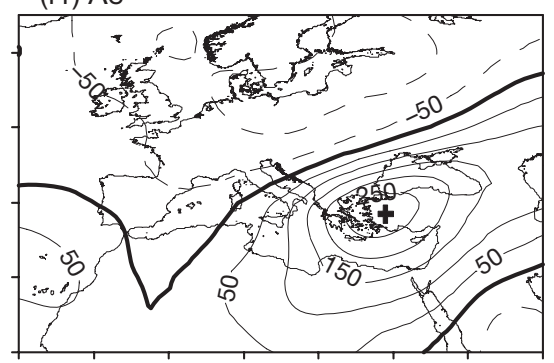

(f2) As

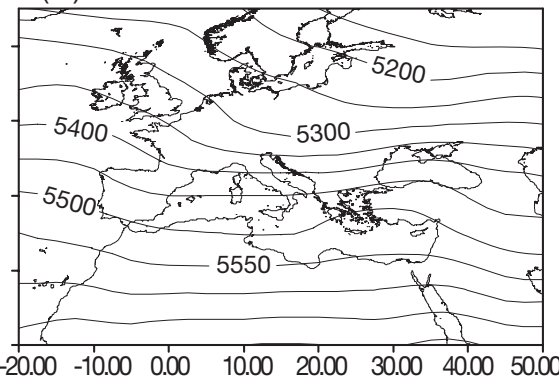

Fig. 2. Winter mean 1000-500 hPa thickness field anomalies $(\mathrm{hPa} \times 10)$ and the corresponding geopotential height for anticyclonic circulation types. Acronyms explained in Table 1 

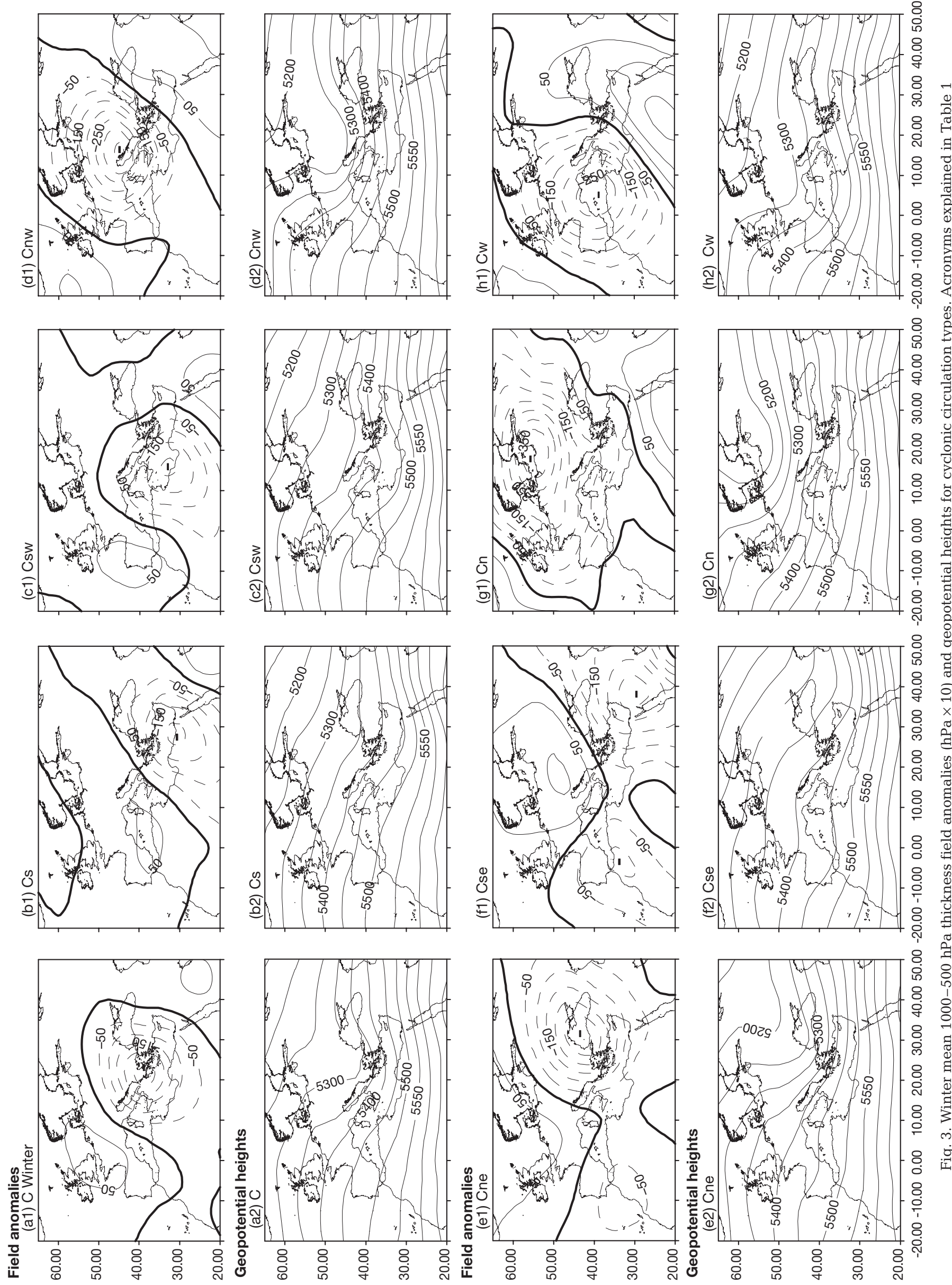
Linear regression was chosen to study the trends Tmax and Tmin on an annual and seasonal basis. The significance of the trends, was verified by Spearman's rank correlation test (Sneyers 1992) at $\alpha=0.05$.

A circulation-type statistical model was developed to perform downscaling of extreme temperatures in the Greek area (see Section 5). For this purpose multiple linear regression analysis was employed (Wilks 1995).

Table 1. Seasonal and annual frequencies (\%) of the 14 circulation types for the period 1958-2000. Acronyms: circulation types (A: anticyclonic, C: cyclonic) followed by location of positive or negative anomaly centres in relation to Greece (absence of location information indicates anomaly centre directly over Greece)

\begin{tabular}{|lrrrrr|}
\hline & Winter & Spring & Summer & Autumn & Year \\
\hline Anw & 6.6 & 5.5 & 14.6 & 11.3 & 9.5 \\
Ane & 5.8 & 4.9 & 6.1 & 7.2 & 6.0 \\
A & 7.3 & 4.9 & 10.4 & 8.6 & 7.8 \\
Asw & 9.8 & 14.1 & 13.6 & 12.2 & 12.4 \\
Ase & 4.3 & 6.4 & 13.1 & 10.4 & 8.6 \\
Ae & 1.0 & 3.4 & 7.1 & 2.2 & 3.5 \\
C & 13.7 & 10.3 & 11.3 & 11.8 & 11.8 \\
Cs & 6.3 & 7.9 & 4.8 & 6.3 & 6.3 \\
Csw & 16.2 & 16.6 & 6.0 & 11.0 & 12.5 \\
Cnw & 6.6 & 5.5 & 3.4 & 4.8 & 5.1 \\
Cne & 14.6 & 13.0 & 7.6 & 9.4 & 11.1 \\
Cse & 2.6 & 3.1 & 0.8 & 2.0 & 2.1 \\
Cn & 0.5 & 0.7 & 0.3 & 0.3 & 0.4 \\
Cw & 4.8 & 3.8 & 0.9 & 2.5 & 3.0 \\
\hline
\end{tabular}

The correlation coefficient, the differences, the differences of the standard deviation (SD) and the Root Mean Square Error (RMSE) were used in order to assess the performance of the downscaling method.

\section{TREND ANALYSIS}

\subsection{Extreme temperature}

Winter Tmin (Table 2a) tends to decrease interannually over the Greek area, with statistical significance for the southern Peloponnesus and some Aegean islands. In contrast, a trend of increasing Tmin is apparent during summer; statistically significant, however, only for 3 stations (Kythira, Larissa, Naxos). In spring and autumn, a statistically significant negative tendency predominates. Although the number of stations with positive and negative trends is equal, the magnitude of the negative trends is higher than that of the positive ones. However, the negative annual trends are statistically significant for only 2 stations (Samos and Tripoli).

Tmin10p presents a general decreasing tendency on an annual basis, with statistical significance over western Greece, western Crete and the eastern Aegean (Table $2 \mathrm{~b}$ ). The negative values in spring and autumn seem to mostly account for this annual decreasing tendency. In contrast, winter negative values were found mainly in western Greece, while in summer there was a positive trend over the whole of the Greek area.

Table 2. Trends of mean seasonal and annual minima. (a) Daily minimum temperatures (Tmin), (b) 10th percentile for minimum temperature (Tmin10p). Bold: statistically significant

\begin{tabular}{|c|c|c|c|c|c|c|c|c|c|c|}
\hline & \multicolumn{5}{|c|}{ (a) Mean Tmin } & \multicolumn{5}{|c|}{ (b) Mean Tmin10p } \\
\hline & DJF & MAM & JJA & $\mathrm{SON}$ & Year & DJF & MAM & JJA & SON & Year \\
\hline Agrinio & -0.44 & -0.28 & 0.18 & -0.27 & -0.20 & -0.44 & -0.69 & 0.26 & -0.57 & -0.65 \\
\hline Alexandroupoli & -0.18 & 0.01 & 0.18 & -0.16 & -0.04 & -0.06 & -0.17 & 0.18 & -0.45 & -0.18 \\
\hline Athens & -0.06 & -0.01 & 0.20 & 0.11 & 0.07 & 0.08 & -0.26 & 0.33 & -0.31 & -0.10 \\
\hline Elliniko & -0.15 & -0.22 & -0.03 & -0.01 & -0.10 & 0.03 & -0.33 & -0.04 & -0.32 & -0.20 \\
\hline Heraklio & -0.02 & 0.03 & 0.23 & 0.15 & 0.10 & 0.10 & -0.20 & 0.16 & -0.06 & -0.02 \\
\hline Ierapetra & 0.15 & 0.09 & 0.20 & 0.03 & 0.12 & 0.34 & -0.05 & 0.37 & -0.01 & 0.15 \\
\hline Ioannina & -0.09 & -0.12 & 0.22 & 0.02 & 0.00 & 0.05 & -0.30 & 0.23 & -0.25 & -0.18 \\
\hline Kalamata & -0.44 & -0.30 & 0.06 & -0.27 & -0.24 & -0.47 & -0.60 & 0.16 & -0.50 & -0.54 \\
\hline Kerkyra & 0.00 & 0.09 & 0.17 & 0.12 & 0.10 & 0.38 & 0.00 & 0.26 & 0.04 & -0.01 \\
\hline Kozani & 0.19 & 0.09 & 0.24 & 0.08 & 0.14 & 0.43 & -0.21 & 0.50 & -0.36 & 0.06 \\
\hline Kythira & 0.07 & 0.05 & 0.28 & 0.20 & 0.15 & 0.11 & -0.01 & 0.32 & -0.13 & 0.02 \\
\hline Larissa & -0.05 & 0.05 & 0.26 & 0.05 & 0.07 & -0.01 & -0.22 & 0.34 & -0.23 & -0.13 \\
\hline Milos & -0.12 & -0.18 & 0.02 & -0.02 & -0.08 & 0.01 & -0.27 & 0.05 & -0.46 & -0.19 \\
\hline Mytilini & -0.28 & -0.15 & 0.13 & -0.12 & -0.10 & -0.09 & -0.29 & 0.17 & -0.52 & -0.33 \\
\hline Naxos & 0.13 & 0.13 & 0.31 & 0.30 & 0.21 & 0.40 & 0.02 & 0.35 & 0.10 & 0.11 \\
\hline Rodos & 0.11 & 0.10 & 0.18 & 0.16 & 0.14 & 0.56 & 0.17 & 0.25 & 0.14 & 0.22 \\
\hline Samos & -0.66 & -0.21 & 0.23 & -0.55 & -0.29 & -0.60 & -0.61 & -0.11 & -1.09 & -0.71 \\
\hline Skyros & -0.28 & -0.18 & 0.07 & -0.12 & -0.13 & -0.17 & -0.48 & 0.23 & -0.44 & -0.35 \\
\hline Thessaloniki & 0.06 & -0.09 & 0.04 & -0.16 & -0.03 & 0.13 & -0.21 & 0.14 & -0.61 & 0.06 \\
\hline Tripoli & -0.38 & -0.23 & -0.17 & -0.36 & -0.30 & -0.54 & -0.57 & 0.00 & -0.64 & -0.60 \\
\hline
\end{tabular}


Table 3. Trends of mean seasonal and annual maxima. (a) Daily maximum temperatures (Tmax), (b) 90th percentile for maximum temperature (Tmax90p). Bold: statistically significant

\begin{tabular}{|c|c|c|c|c|c|c|c|c|c|c|}
\hline & \multicolumn{5}{|c|}{ (a) Mean Tmax } & \multicolumn{5}{|c|}{ (b) Mean Tmax90p } \\
\hline & DJF & MAM & JJA & SON & Year & DJF & MAM & JJA & SON & Year \\
\hline Agrinio & -0.17 & -0.01 & 0.02 & -0.14 & -0.08 & -0.29 & 0.07 & -0.03 & -0.14 & -0.06 \\
\hline Alexandroupoli & -0.13 & 0.02 & 0.16 & -0.16 & -0.03 & -0.24 & 0.12 & 0.25 & 0.07 & 0.11 \\
\hline Athens & 0.01 & 0.28 & 0.56 & 0.18 & 0.26 & -0.04 & 0.49 & 0.47 & 0.34 & 0.52 \\
\hline Elliniko & -0.25 & -0.08 & 0.27 & -0.10 & -0.05 & -0.39 & 0.07 & 0.24 & 0.11 & 0.20 \\
\hline Heraklio & -0.28 & -0.16 & -0.08 & -0.06 & -0.15 & -0.36 & -0.11 & -0.16 & -0.04 & -0.08 \\
\hline Ierapetra & -0.34 & -0.19 & 0.15 & -0.12 & -0.12 & -0.50 & 0.14 & 0.28 & 0.05 & 0.16 \\
\hline Ioannina & -0.19 & -0.08 & 0.22 & -0.25 & -0.08 & -0.38 & -0.06 & 0.30 & -0.33 & 0.09 \\
\hline Kalamata & -0.40 & -0.16 & 0.15 & -0.27 & -0.17 & -0.65 & 0.16 & 0.11 & -0.06 & 0.11 \\
\hline Kerkyra & -0.02 & 0.04 & 0.25 & 0.02 & 0.07 & -0.07 & 0.12 & 0.32 & -0.03 & 0.21 \\
\hline Kozani & -0.01 & -0.02 & 0.25 & -0.14 & 0.01 & 0.09 & -0.08 & 0.24 & 0.14 & 0.19 \\
\hline Kythira & -0.34 & -0.18 & 0.11 & -0.09 & -0.13 & -0.43 & -0.07 & 0.14 & 0.02 & 0.04 \\
\hline Larissa & -0.10 & 0.05 & 0.09 & -0.08 & -0.02 & -0.28 & 0.09 & 0.08 & 0.15 & 0.03 \\
\hline MÈlos & -0.19 & 0.06 & 0.37 & 0.04 & 0.07 & -0.29 & 0.19 & 0.31 & 0.19 & 0.25 \\
\hline Mytilini & -0.24 & 0.02 & 0.28 & -0.03 & 0.00 & -0.20 & 0.24 & 0.24 & 0.20 & 0.28 \\
\hline Naxos & -0.15 & 0.06 & 0.29 & 0.15 & 0.09 & -0.18 & 0.22 & 0.29 & 0.60 & 0.35 \\
\hline Rodos & -0.26 & -0.17 & 0.01 & -0.28 & -0.17 & -0.42 & -0.18 & -0.14 & -0.17 & -0.11 \\
\hline Samos & -0.07 & 0.08 & 0.18 & -0.03 & 0.04 & -0.16 & 0.37 & 0.41 & 0.16 & 0.26 \\
\hline Skyros & -0.35 & -0.07 & 0.14 & -0.07 & -0.09 & -0.38 & -0.09 & 0.21 & 0.35 & 0.13 \\
\hline Thessaloniki & 0.07 & 0.05 & 0.27 & -0.03 & 0.08 & -0.08 & 0.08 & 0.20 & 0.27 & 0.21 \\
\hline Tripoli & -0.09 & 0.18 & 0.20 & -0.36 & -0.02 & 0.02 & 0.27 & 0.44 & -0.33 & 0.21 \\
\hline
\end{tabular}

Annual positive trends in Naxos and Rodos seem to be caused by changes (statistically significant positive trends) observed in winter.

Maximum temperature (Table 3a) is characterized by an overall negative trend over the Greek area during winter, which is however, statistically significant only over Crete and the southern Aegean Sea and southern Peloponnesus. In contrast, the summer maximum temperature appears to increase in all stations (except for Heraklio), with statistically significant values over Athens, the Cyclades and Thessaloniki. During the other seasons, the sign of the trend seems to vary from station to, with positive (negative) sign being more prominent in spring (autumn), although statistical significance of these results occurs for only a few stations. A generally negative trend is observed for annual maximum temperature. Only Athens presents a statistically significant positive trend, which can be attributed to the urban heat island effect (Xoplaki 2002).

Tmax90p seems to increase throughout the whole period, with statistically significant values for the Athens area and the islands of the central and eastern Aegean Sea. The annual trend of increasing Tmax90p seems to be mainly associated with the positive values during spring and summer, although these are statistically significant only over a limited number of non-contiguous stations. In contrast, winter Tmax90p is characterized by negative trend values over the whole area that are statistically significant over southern Greece, the central Aegean and NW Greece. In autumn, Tmax90p tends to decrease in western Greece and in- crease in the remaining Greek area. Statistically significant values are found mainly over the central Aegean.

\subsection{Circulation types}

The annual frequencies of the 6 anticyclonic types and the 8 cyclonic types are 47.8 and $52.3 \%$, respectively (see Table 1). The cyclonic types present the highest seasonal percentage $(65.8 \%$, during winter), while the summer frequency of the anticyclonic types is $64.9 \%$. Asw and Csw are the 2 most frequent circulation types, for both types the anomaly centres are located over SW Greece. Table 4 shows the direction of the trends in frequency of the circulation types over the Greek area. The frequency of occurrence of the majority of anticyclonic types show statistically significant positive trends on an annual basis, while the majority of the cyclonic types present negative trends. The same behaviour is apparent on a seasonal basis, but results are statistically significant for only a limited number of types.

\section{RELATIONSHIP BETWEEN TEMPERATURE AND CIRCULATION TYPES}

In order to investigate the relationship between temperature and circulation types, the deviation of the mean Tmin or Tmax associated with each circulation type from its average value for each station (hereafter 
referred to as anomaly) was calculated on an annual and seasonal basis.

Fig. 4 shows the magnitude of the anomalies of winter minimum temperature for each circulation type and station, and Table 5 presents the direction of trends with statistically significant trends at $\alpha=0.05$. Circulation types Ane, A, Asw and Ae form strong positive anomalies, while Anw forms weak positive or negative anomalies. In contrast, the cyclonic types $\mathrm{C}$, Cs, Cne and Cse present strong negative anomalies, while the other types are associated with relatively positive anomalies. It should be also noted that on an annual

Table 4. Seasonal and annual trends (positive or negative) of frequency of the 14 circulation types for the period 1958-2000. Shading: statistically significant. See Table 1 for explanation of acronyms

\begin{tabular}{|lccccc|}
\hline & Winter & Spring & Summer & Autumn & Year \\
\hline Anw & + & + & + & - & + \\
Ane & + & + & + & + & + \\
A & + & + & + & + & + \\
Asw & - & + & + & + & + \\
Ase & + & + & + & + & + \\
Ae & - & - & + & - & - \\
C & - & + & - & - & - \\
Cs & - & - & - & - & - \\
Csw & - & - & - & - & - \\
Cnw & - & + & + & - & + \\
Cne & - & + & - & + & + \\
Cse & - & - & - & + & - \\
Cn & - & - & - & + & - \\
Cw & - & - & - & - & - \\
\hline
\end{tabular}

basis (not shown) the anticyclonic (cyclonic) types are characterized by positive (negative) anomalies.

Furthermore, the winter trends of Tmin anomalies (Table 5) present a decreasing tendency, which becomes evident for both anticyclonic and cyclonic types. The only apparent exceptions are Ase (anticyclonic) and $\mathrm{C}$ and $\mathrm{Cnw}$ (cyclonic), where for half of the stations and for the majority of the stations, respectively, the trends are positive. This overall decreasing tendency may be partially attributed to the general increase in frequency of surface anticyclonic types, which is related to northerly, northwesterly or northeasterly airflows over Greece (Maheras et al. 2000a). This is broadly in agreement with the results of Feidas et al. (2004), who demonstrated that the enhanced frequency of northerly or northeasterly continental dry and cold airflows over Greece from northern Europe and western Russia were related to the trend of decreasing temperature. Moreover, it is associated with the increase in frequency and persistence of the surface cold anticyclonic types over the Mediterranean and Balkans (Maheras \& Kutiel 1999, Maheras et al. 2000a).

Fig. 5 shows the magnitude of the anomalies of summer Tmax for each circulation type and station, and Table 6 presents the direction of trends, with statistically significant trends at $\alpha=0.05$. Anticyclonic (cyclonic) types present positive (negative) anomalies for almost all the stations. Circulation type A presents the greatest positive anomalies, while the types C, Csw and Cne present the greatest negative anomalies for almost all stations. Moreover, it can be seen that during summer the majority of the stations exhibit positive

Table 5. Trends (positive or negative) of winter Tmin for each circulation type. Shading: statistically significant. 0: no trend. See Table 1 for explanation of acronyms

\begin{tabular}{|c|c|c|c|c|c|c|c|c|c|c|c|c|c|c|}
\hline & \multicolumn{14}{|c|}{ Circulation type } \\
\hline & Anw & Ane & $\mathrm{A}$ & Asw & Ase & $\mathrm{Ae}$ & $\mathrm{C}$ & $\mathrm{Cs}$ & Csw & Cnw & Cne & Cse & $\mathrm{Cn}$ & $\mathrm{Cw}$ \\
\hline Agrinio & - & - & - & - & - & - & + & - & - & + & - & - & - & - \\
\hline Alexandroupoli & - & - & - & - & + & - & + & - & - & + & - & + & - & - \\
\hline Athens & - & - & - & - & + & - & + & - & - & + & - & - & - & - \\
\hline Elliniko & - & - & - & - & - & - & + & - & - & + & - & - & - & - \\
\hline Herakleio & - & - & - & - & + & + & + & + & + & + & + & - & - & + \\
\hline Ierapetra & + & - & - & + & - & - & + & - & - & + & + & - & - & - \\
\hline Ioannina & + & - & + & + & + & - & + & + & + & + & + & + & - & + \\
\hline Kalamata & - & - & - & - & + & + & + & - & - & + & - & - & - & - \\
\hline Kerkyra & - & - & - & - & - & - & - & - & - & - & - & - & - & - \\
\hline Kozani & - & - & + & - & + & + & + & + & + & + & + & + & - & - \\
\hline Kythira & - & - & - & + & + & + & + & - & + & + & + & - & - & + \\
\hline Larissa & - & - & - & - & + & - & + & - & - & + & - & - & - & + \\
\hline Milos & - & - & - & - & - & - & + & - & - & + & - & + & - & - \\
\hline Mytilini & - & - & - & - & - & + & - & - & - & + & - & - & - & - \\
\hline Naxos & + & - & + & + & - & - & + & + & + & + & + & + & - & - \\
\hline Rodos & + & + & + & + & - & + & + & - & - & + & 0 & + & - & - \\
\hline Samos & - & - & - & - & - & - & - & - & - & - & - & - & - & - \\
\hline Skyros & - & - & - & - & - & - & + & - & - & + & - & - & - & - \\
\hline Thessaloniki & + & - & - & + & + & - & + & + & - & + & + & + & - & - \\
\hline Tripoli & - & - & - & - & + & - & - & - & - & + & - & - & - & + \\
\hline
\end{tabular}




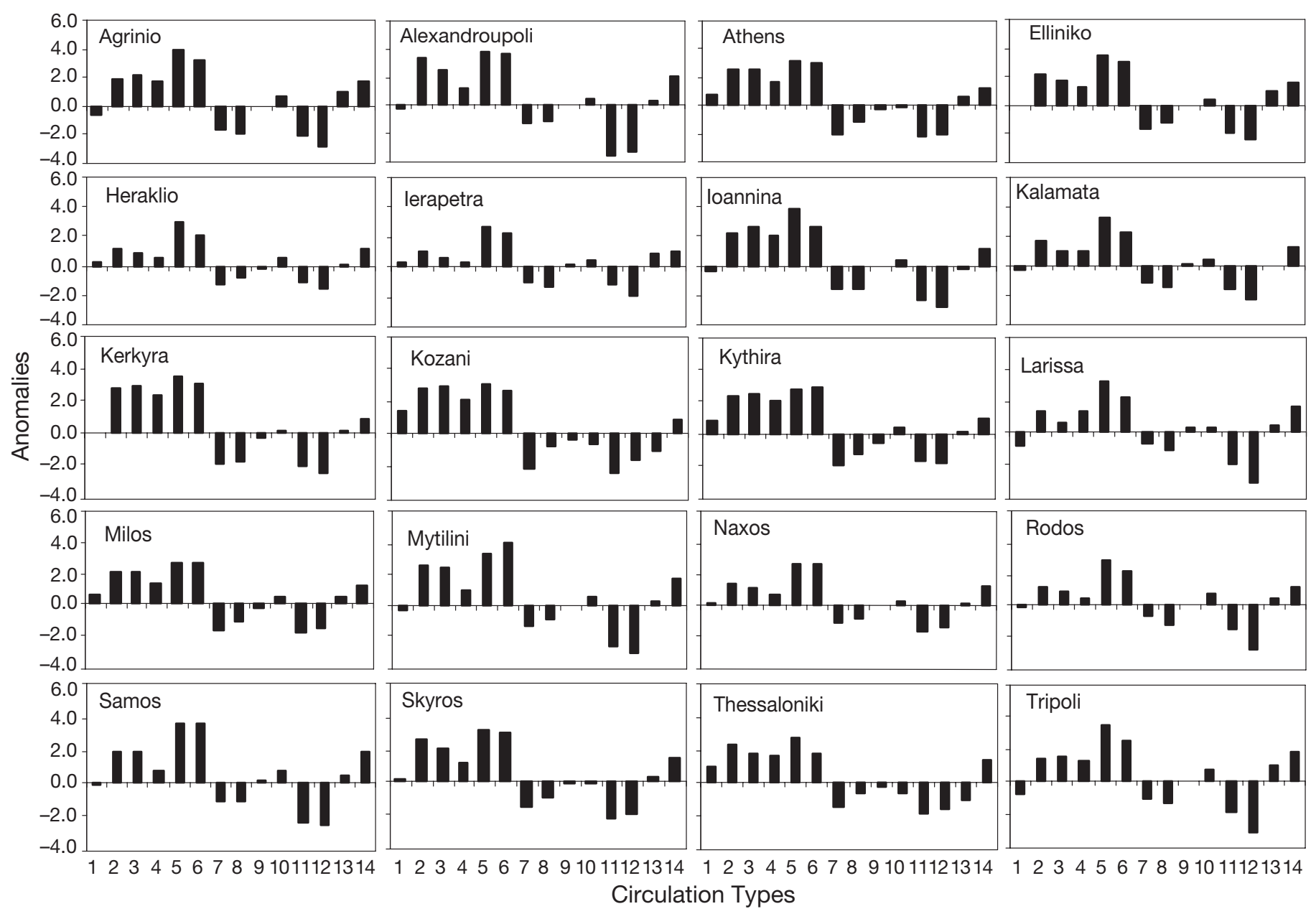

Fig. 4. Winter minimum temperature anomalies $\left({ }^{\circ} \mathrm{C}\right)$ at the 20 Greek stations, for the 14 circulation types. $x$-axis: circulation types $(1=$ Anw, $2=$ Ane, $3=\mathrm{A}, 4=\mathrm{Asw}, 5=\mathrm{Ase}, 6=\mathrm{Ae}, 7=\mathrm{C}, 8=\mathrm{Cs}, 9=\mathrm{Csw}, 10=\mathrm{Cnw}, 11=\mathrm{Cne}, 12=\mathrm{Cse}, 13=\mathrm{Cn}, 14=\mathrm{Cw})$

trends for frequency of most of the circulation types (Table 5), except for $\mathrm{Ae}, \mathrm{Csw}, \mathrm{Cn}$ and $\mathrm{Cw}$.

Therefore, it is suggested that the increase in frequency of the anticyclonic types can explain the trend of increasing summer Tmax. This leads to an identified westerly to southwesterly wind advecting warm air masses from Northern Africa over Greece or an anomalous northeasterly to easterly continental flow and subsidence at the upper levels. In addition, according to Feidas et al. (2004, p. 200) '...positive pressure trend is limited to the southeastern Mediterranean, the Middle East and Turkey' and 'The increasing trend in pressure indicates a less frequent expansion of the low over the southeastern Mediterranean and therefore a weakening of the Etesian winds and a subsequent increase in summer temperatures'. These synoptic situations contribute to an increase in stability and result in the formation of clear skies and maximum insolation conditions. This finding is in agreement with Bartzokas \& Metaxas (1991), Metaxas et al. (1991), Maheras \& Kutiel (1999) and Xoplaki et al. (2003).

\section{STATISTICAL MODEL}

GCMs remain the most appropriate tool to estimate future global-scale climate changes for an atmosphere enhanced with greenhouse gases. However, GCMs have proved to be ineffective in simulating regional variables, due to their relatively low spatial resolution of a few 100s of kilometres. This spatial scale mismatch can be overcome by applying to the GCM data a statistical downscaling technique. According to Busuioc et al. (2001) the performance of a statistical downscaling model depends on 3 main conditions: (1) the link between predictands and predictors should be strong and explain satisfactorily the variability of temperature or precipitation, (2) the relationship between predictands and predictors should be time invariant and (3) the predictor variables should be well simulated by the GCM.

Multiple linear regression is a generalization of simple linear regression (Wilks 1995). Similarly to simple linear regression, there is a single predictand during 


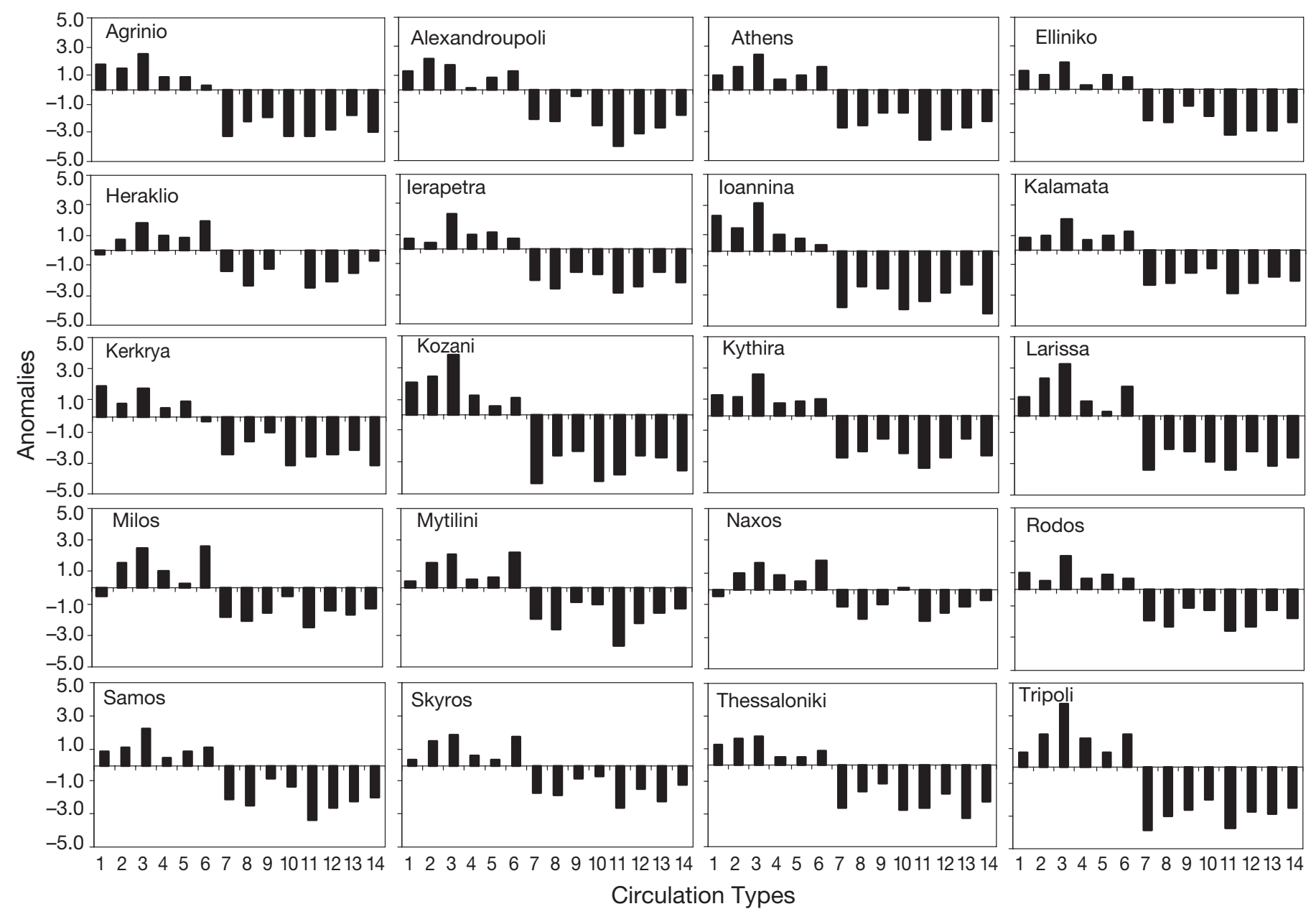

Fig. 5. As in Fig. 4, but for maximum summer temperature anomalies

the whole procedure, but multiple regression opens up the possibility of an unlimited number of potential predictor variables. Goodess \& Jones (2002) argued that the main purposes of the regression analysis are 'to identify the best circulation based predictor variables ... to determine whether and, if so, how they vary over space and/or time and whether or not the resulting models can explain the observed rainfall trends and/or have the sufficient skill for downscaling.'

Correlation analysis between seasonal temperature (Tmin, Tmax) and corresponding frequency of anticyclonic and cyclonic circulation types at the 1000 to $500 \mathrm{hPa}$ thickness field for Greece revealed for all seasons the correlation coefficients between Tmin/Tmax and the frequency of the anticyclonic types are positive. On the other hand, the correlation coefficients between Tmin/Tmax, and the frequency of the cyclonic types are negative (Table 7).

In climatological applications the physical and/or statistical relationships between predictors and predictands can be different in distinct seasons. For this reason we produced separate models for each season and station. To quantify and describe the skill of the model, the coefficient of determination $\mathrm{R}^{2}$ was calculated. For a better evaluation of the model results, the differences between the observed and simulated values were also calculated, as well as the corresponding differences of the SD of the 2 datasets. The statistical significance of the derived values was tested with the aid of a $t$-test.

The statistical model was developed in 3 stages (Fig. 6). In the first stage and for the calibration period (1958-1978 and 1994-2000), the predictors were the circulation-type frequencies and the predictands were Tmax and Tmin while multiple linear regression analysis was used for all possible combinations for the circulation types. In the second stage, the best of each circulation types group (each circulation type separately, each pair of circulation types, each triplet, each quadruplet, etc.) was selected using the highest $\mathrm{R}^{2}$ of the analysis. Continuously, the simulated data for the validation period (1979-1993), as derived from these 'best $\mathrm{R}^{2 \prime}$ groups, were compared with the observed data and the simulated group and the highest correla- 
Table 6. Trends (positive or negative) of summer maximum temperatures for each circulation type. Shading: statistically significant. 0: no trend. See Table 1 for explanation of acronyms

\begin{tabular}{lcccccccccccccccc}
\hline & Anw & Ane & A & Asw & Ase & Ae & C & Cs & Csw & Cnw & Cne & Cse & Cn & Cw \\
\hline Agrinio & - & - & - & - & - & - & + & - & - & + & + & - & - \\
Alexandroupoli & - & - & + & - & + & + & + & - & - & + & + & - \\
Athens & + & + & + & + & + & + & + & + & + & + & + & - \\
Elliniko & - & + & + & + & + & + & + & - & - & + & + & - & - \\
Heraklio & - & - & + & + & + & + & + & - & + & + & + & + & - \\
Ierapetra & - & - & - & - & - & - & - & - & - & + & - & - & - \\
Ioannina & - & - & + & - & - & - & + & - & - & + & + & - & - \\
Kalamata & - & - & + & - & - & + & + & - & + & + & + & - & - \\
Kerkyra & - & - & + & + & + & - & + & + & - & + & + & + & - \\
Kozani & 0 & - & + & + & - & - & + & - & + & + & + & - & - \\
Kythira & - & - & + & - & - & - & + & - & - & + & + & - & - \\
Larissa & - & - & - & - & - & - & + & - & - & + & + & + & - \\
Milos & + & + & + & + & + & - & + & + & + & + & + & + & - \\
Mytilini & + & + & + & + & + & - & + & - & - & + & + & - & - \\
Naxos & + & + & + & + & + & - & + & + & - & + & + & + & + \\
Rodos & - & - & - & - & - & - & + & - & - & + & + & - & - \\
Samos & + & + & + & + & + & - & + & - & - & - & - & - & - \\
Skyros & - & + & + & + & + & - & + & + & - & + & + & + & - \\
Thessaloniki & - & + & + & + & + & - & + & + & - & + & + & + & - \\
Tripoli & + & + & + & + & - & - & - & + & - & + & - & - \\
\hline
\end{tabular}

tion coefficient was selected. In the third stage, for each station and for each season, 1 circulation-type group was finally selected, which was then applied to the model, using the frequencies of the circulation types computed by the daily data of the GCM thickness field 1000 to $500 \mathrm{hPa}$ (control run). For this stage, the calibration period was 1958-2000 employing NCEP and station data and the validation period was 1960-1990, employing a GCM control run.

Fig. $7 \mathrm{a}, \mathrm{b}$ summarizes the results of the statistical model for winter Tmin and summer Tmax for the validation period (1979-1993). Correlation coefficients between the observed and simulated temperatures are higher for winter Tmin than for summer Tmax for most of the stations. The only exceptions are Alexandroupoli, Ierapetra, Kalamata, Kozani, Naxos, Samos and Thessaloniki, where summer values are higher. The highest correlation coefficient for winter Tmin was found in Mytilini (0.92) and the lowest in Ierapetra (0.45). In the case of the summer Tmax, the highest correlation coefficient value is found in Kalamata (0.88) and the lowest in Heraklio (0.45). Correlation coefficients for winter Tmax (not shown) are not only higher than the corresponding ones in summer, but also higher than those for winter Tmin. They vary from 0.93 (Athens) to 0.61 (Rodos), while 17 stations presented coefficients with values greater than 0.8 (not shown). During transient seasons, spring and autumn, high correlations are found for both Tmax and Tmin, with values that are higher than the Tmax in summer.

According to Fig. $7 \mathrm{c}, \mathrm{d}$, the differences of both Tmin and Tmax are positive (except for Tripoli for winter
Table 7. Correlation coefficients between seasonal frequency of circulation types and corresponding daily maximum (Tmax) and minimum (Tmin) temperatures for all stations (averaged). Level of statistical significance is 0.05 ; correlation coefficients $>0.26$ are significant

\begin{tabular}{|clcc|}
\hline & & Anticyclonic & Cyclonic \\
\hline Winter & Tmin & 0.65 & -0.60 \\
& Tmax & 0.75 & -0.69 \\
Spring & Tmin & 0.61 & -0.63 \\
& Tmax & 0.73 & -0.81 \\
Summer & Tmin & 0.61 & -0.67 \\
& Tmax & 0.74 & -0.82 \\
Autumn & Tmin & 0.63 & -0.69 \\
& Tmax & 0.62 & -0.74 \\
\hline
\end{tabular}

Tmin and Naxos for summer Tmax, which present slightly negative differences). The positive differences vary between $0.1^{\circ} \mathrm{C}$ (Thessaloniki) and $1.2^{\circ} \mathrm{C}$ (Agrinio and Samos) for Tmin, and from $0.1^{\circ} \mathrm{C}$ (Tripoli) to $1^{\circ} \mathrm{C}$ (Elliniko) for Tmax. Therefore, there is a small overestimation of the extreme temperature values as calculated by the model. This overestimation is statistically significant for 3 stations in the case of winter Tmin (Agrinio, Kalamata and Samos) and for 6 stations in the case of the summer Tmax (Agrinio, Elliniko, Heraklio, Ierapetra, Milos and Mytilini). It should be noted that these stations, except Agrinio, are located near the coast.

Contrary to the values of extreme temperature, the values of the simulated SDs, for 13 stations for winter Tmin and for 14 stations for summer Tmax, are lower 


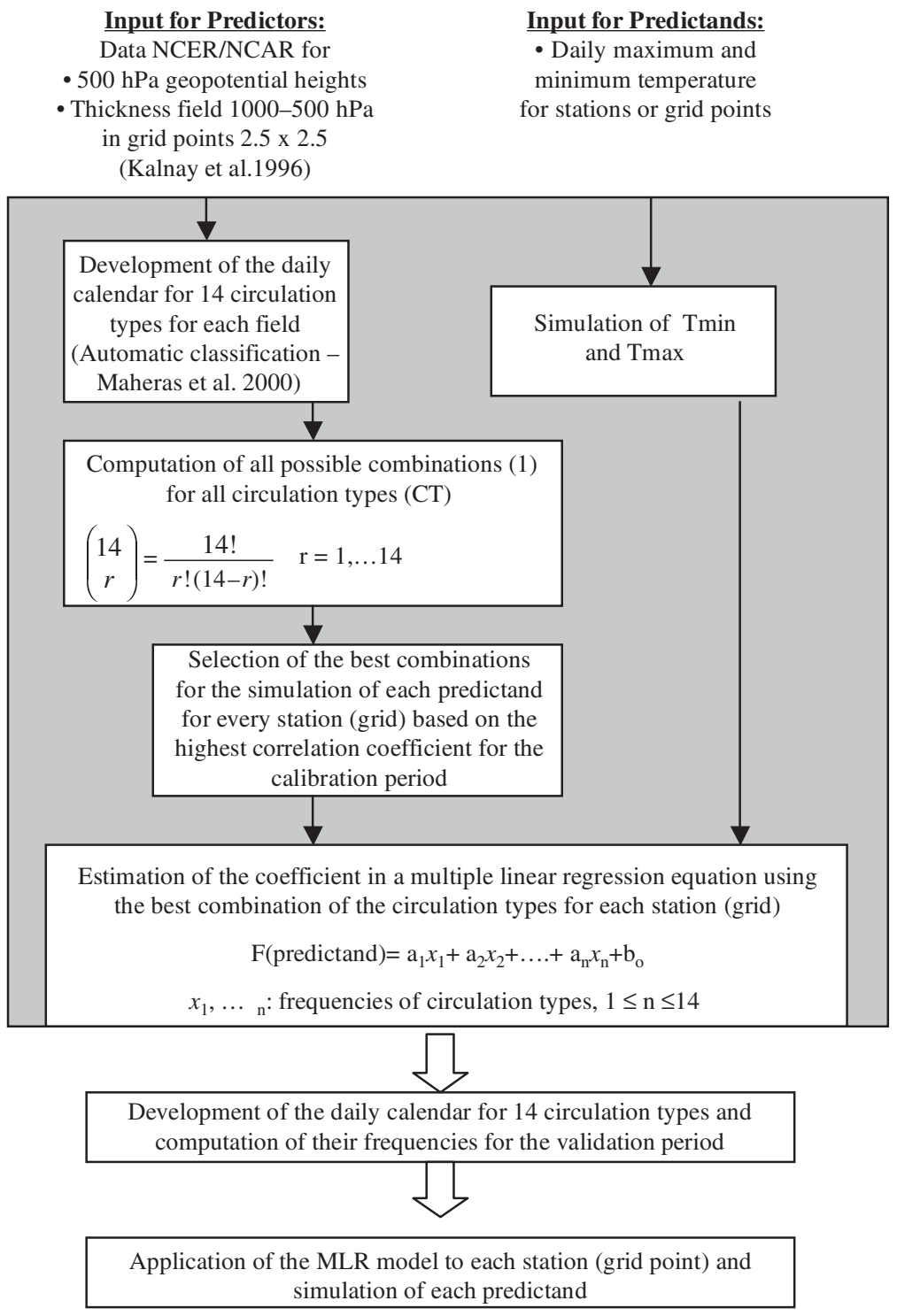

Fig. 6. Development of algorithm of the Multiple Linear Regression (MLR) Model based on a circulation-type approach used in the study

\section{HadAM3P CONTROL RUN VALIDATION}

HadAM3P skill in reproducing the regional circulation was assessed by comparing the seasonal frequencies of the 2 individual classifications of circulation types (HadAM3P and NCEP 1000 to $500 \mathrm{hPa}$ thickness field) as well as the biases of the regional composite mean geopotential patterns for individual circulation types. According to the results of this comparison (not shown), the frequency of all anticyclonic and cyclonic circulation types agrees well between the 2 datasets. Both in winter and summer, the frequency of almost all anticyclonic and cyclonic circulation patterns (CPs) together, derived from the GCM dataset, was found to correspond very closely to the values of the NCEP dataset.

However, the GCM tends to show biase in the frequency of certain cyclonic and anticyclonic patterns. For example, circulation types $\mathrm{A}$ and $\mathrm{C}$, whose centers are located over the Greek area, occur more frequently than the corresponding circulation types in the NCEP. Nevertheless, composite mean geopotential patterns for individual CPs in the GCM seem very similar to those in NCEP during the 4 seasons (not shown). Most composites clearly reflect the mean geopotential bias in the respective season, suggesting that the GCM circulation bias is primarily a mean phenomenon rather than resulting from specific weather situations. The bias in variability, especially the overestimation of summer thickness SD values over the eastern Mediterranean, seems to be than the observed SDs. This suggests that for the majority of the stations the simulated series present lower year to year variability than the observed ones. The rest of the stations ( 7 for the winter Tmin and 6 for the summer Tmax), present higher simulated variability. These SD differences (positive or negative) are statistically significant for 4 stations (winter Tmin) and for 5 stations (summer Tmax).

Finally, the root mean square error (RMSE) was calculated (Fig. 7g,h), as a measure of the linear association between the 2 datasets (observed and simulated), to assess the performance of the downscaling method. A lower RMSE represents better model performance. The RMSE values show a slight regional variation, being lower for winter Tmin than for summer Tmax. systematic in most of the CPs. However, it seems that this does not affect the downscaling performance of the model for the simulation of the summer Tmax values.

The downscaling methodology applied to the HadAM3P data (control run) was evaluated by comparing present day downscaled scenarios based on GCM output (1960-1990) with observations. Table 8 shows values of observed and downscaled winter Tmin and summer Tmax (due to the fact that the interest for the extreme temperatures is stronger for the minimum winter temperatures and the maximum summer temperatures, the results for the minimum and the maximum temperatures of the regression analysis are only presented for winter and summer). Winter Tmin values are underestimated for all stations (in comparison to the 
Tmin Winter
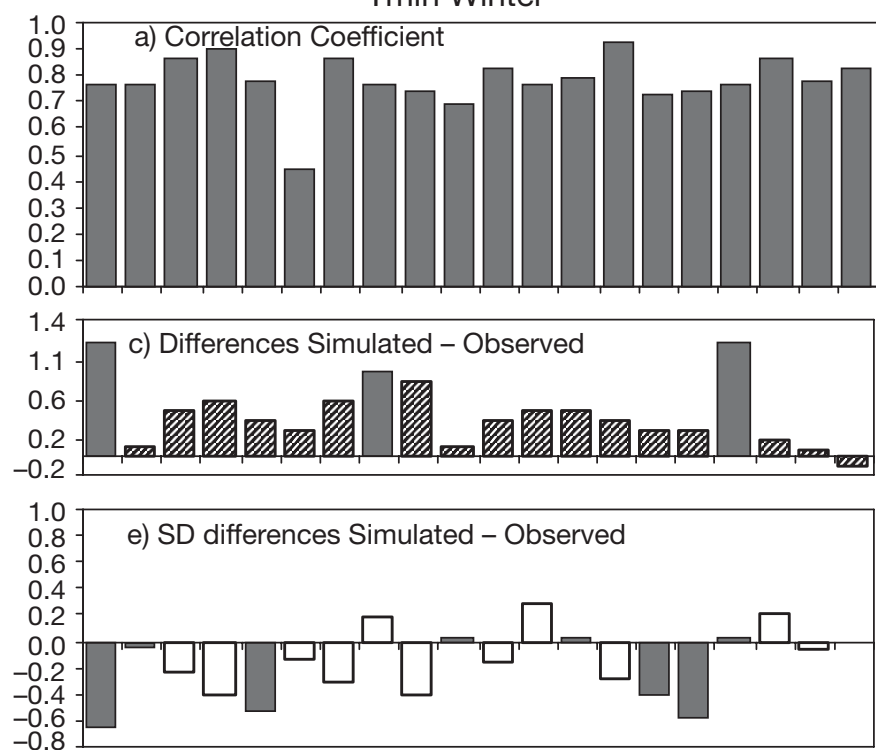

$-0.6$

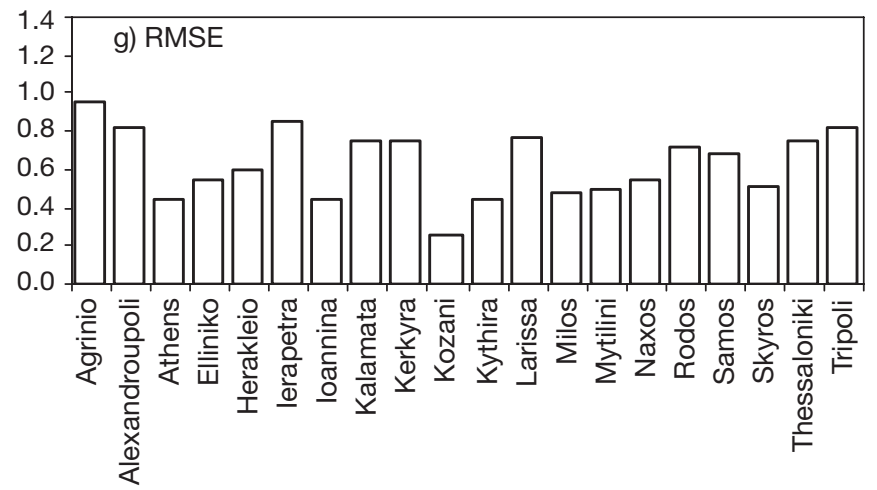

Tmax Summer
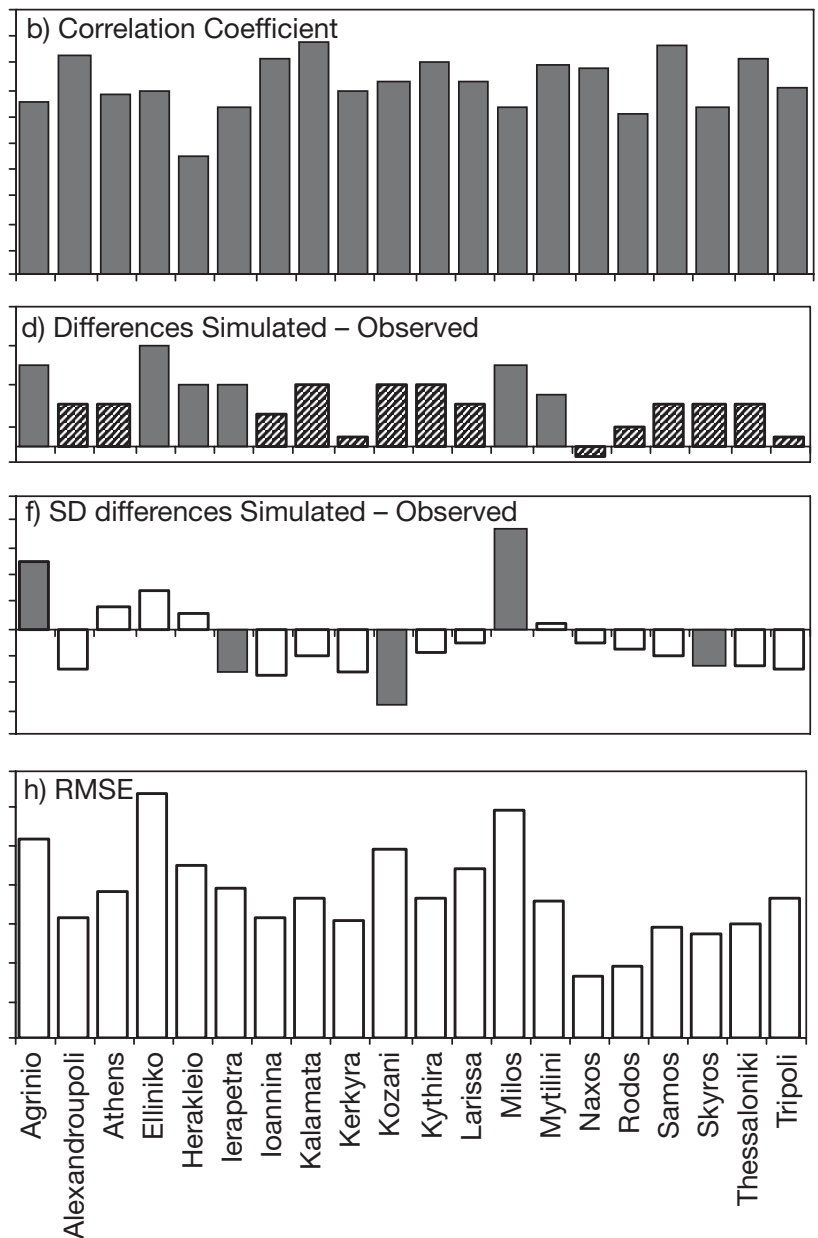

Fig. 7. Results of the statistical model for daily minimum (Tmin) winter values (left column) and daily maximum (Tmax) summer values (right column) for the validation period for all stations. $(\mathrm{a}, \mathrm{b})$ Correlation between simulated and observed values; $(\mathrm{c}, \mathrm{d})$ difference between mean observed and simulated values $\left({ }^{\circ} \mathrm{C}\right)_{i}(\mathrm{e}, \mathrm{f})$ difference between $\mathrm{SD}$ of observed and simulated values $\left({ }^{\circ} \mathrm{C}\right) ;$ $(\mathrm{g}, \mathrm{h})$ RMSE: root mean square error. Level of statistical significance is 0.05 ; correlation coefficients $>0.44$ are statistically significant (dark grey bars)

observed values). These negative differences vary from -0.1 to $-1.2^{\circ} \mathrm{C}$ and are statistically significant in 16 stations. The significance of these differences could be associated with 2 factors: (1) the very low variability of the simulated temperatures and (2) the negative influence of the trend appearing in the calibration period, which seems to affect the simulation and calculation of winter Tmin. The elimination of the trend in this case could lead to more satisfying results. In contrast, the summer Tmax are overestimated in comparison to the observed ones. The positive differences vary from 0 to $0.6^{\circ} \mathrm{C}$, and are statistically significant only for Mytilini.

\section{CONCLUSIONS}

This study explored the relationship between changes in extreme temperature over the Greek area and regional atmospheric circulation, with the aid of a classification scheme based on the 1000 to $500 \mathrm{hPa}$ thickness field. The frequency of anticyclonic circulation types is increasing and that of cyclonic types is decreasing. There is an overall increase (decrease) in the Tmax (Tmin) over the Greek area, with spatial and seasonal variations.

The investigation of the temperature anomalies corresponding to each circulation type revealed that the increase of the frequency of the anticyclonic types could explain the upward trend of Tmax in summer. Furthermore, the number of the cases with statistically significant positive trends in summer Tmax is greater than the ones with statistically significant negative trends. In contrast, the trend of decreasing winter Tmin, especially in central and southwestern Greece, characterised by trends of decreasing positive and negative anomalies for the majority of circulation types, cannot be interpreted 
Table 8. Results of the multiple regression analysis (MLRct) model for the validation period (1960-1990, HadAM3P, control run) for winter Tmin and summer Tmax. Statistically significant differences are bold, $(t$-test; $p=0.05)$. OBS: observed values

\begin{tabular}{|lrrrrrr|}
\hline & \multicolumn{3}{c}{ Winter Tmin } & \multicolumn{3}{c|}{ Summer Tmax } \\
& MLRct & OBS Differences & MLRct & OBS Differences \\
\hline Agrinio & 2.9 & 4.1 & $\mathbf{- 1 . 2}$ & 32.3 & 32.2 & 0.1 \\
Alexandroupoli & 1.4 & 2.1 & $\mathbf{- 0 . 7}$ & 29.3 & 29.1 & 0.2 \\
Athens & 7.0 & 7.3 & -0.3 & 32.1 & 31.6 & 0.5 \\
Elliniko & 7.2 & 7.8 & $\mathbf{- 0 . 6}$ & 30.8 & 30.5 & 0.3 \\
Heraklio & 9.2 & 9.7 & $\mathbf{- 0 . 5}$ & 28.2 & 28.1 & 0.1 \\
Ierapetra & 8.9 & 9.4 & $\mathbf{- 0 . 5}$ & 31.3 & 30.9 & 0.6 \\
Ioannina & 0.0 & 1.1 & $\mathbf{- 1 . 1}$ & 30.0 & 29.7 & 0.3 \\
Kalamata & 5.1 & 6.2 & $\mathbf{- 1 . 1}$ & 30.6 & 30.4 & 0.2 \\
Kerkyra & 4.7 & 5.9 & $\mathbf{- 1 . 2}$ & 30.0 & 30.0 & 0.0 \\
Kozani & -0.9 & -0.7 & -0.2 & 28.6 & 28.2 & 0.4 \\
Kythira & 9.4 & 9.7 & -0.3 & 27.9 & 27.7 & 0.2 \\
Larissa & 0.4 & 1.3 & $\mathbf{- 0 . 9}$ & 32.2 & 32.1 & 0.1 \\
Milos & 8.7 & 9.1 & $\mathbf{- 0 . 4}$ & 28.3 & 28.0 & 0.3 \\
Mytilini & 6.6 & 7.5 & $\mathbf{- 0 . 9}$ & 30.0 & 29.6 & $\mathbf{0 . 4}$ \\
Naxos & 9.8 & 9.9 & -0.1 & 26.4 & 26.2 & 0.2 \\
Rodos & 10.1 & 10.5 & $\mathbf{- 0 . 4}$ & 28.8 & 28.8 & 0.0 \\
Samos & 7.2 & 8.4 & $\mathbf{- 1 . 2}$ & 31.7 & 31.4 & 0.3 \\
Skyros & 7.3 & 8.2 & $\mathbf{- 0 . 9}$ & 27.2 & 27.0 & 0.2 \\
Thessaloniki & 2.7 & 3.3 & $\mathbf{- 0 . 6}$ & 30.6 & 30.3 & 0.3 \\
Tripoli & 0.8 & 1.7 & $\mathbf{- 0 . 9}$ & 29.6 & 29.5 & 0.1 \\
\hline
\end{tabular}

only by changes in circulation-type frequency, as derived by the classification scheme employed in this study. The observed trend of decreasing winter Tmin, accompanied by a trend of decreasing winter Tmax, contributes to a clear cooling trend. Comparison between Greece and the Northern Hemisphere shows that Greece does not follow the marked positive trend of winter Tmin and Tmax observed in the Northern Hemisphere (IPCC 1996, Feidas et al. 2004).

A statistical model based on a circulation-type downscaling approach was developed in order to construct future extreme temperature scenarios for Greece. The statistical downscaling model produces slightly overestimated values of extreme temperature compared to the station data, especially for summer Tmax in coastal stations. Smaller scale processes, such as convective processes, or other local factors not well captured by the regional circulation, are likely to have caused this effect. The simulated series also presents lower year to year variability than the observed series. This result is similar to that obtained in other studies of temperature (Solman \& Nunez 1999, Bergant \& Kajfež-Bogataj 2005) and precipitation (Goodess \& Jones 2002, Maheras et al. 2004). In our case, this well known behaviour of statistical downscaling models (lower variability of estimated temperatures), could be related to (1) the short calibration period, (2) the uncertainties caused by the reanalysis data and (3) the selection of the relevant predictors.

The model was applied to the present day climate simulations provided by the HadAM3P General Circu- lation Model. The estimated winter Tmin and summer Tmax values present many similarities with the observational data, with an underestimation for winter Tmin and a slight overestimation for summer Tmax. Both, Tmin underestimations and Tmax overestimations could be related to a negative or positive trend appearing in the calibration period (1958-2000).

Despite the promising results shown, our method has some limitations. (1) A longer time series should yield more consistent results, as a greater natural variability would be considered. (2) As in all statistical approaches, the time series used are non-stationary. Therefore, we cannot be sure if the relationships between the predictor and predictands will still be valid under future climate conditions. Finally, more satisfactory results might be obtained by using additional predictors, such as temperature at the surface or at various altitudes. A first approach would be to use them as variables in a new classification scheme of circulation types, or, as an alternative, to incorporate them in the regression models. We are working in this direction and hope to present our results in the near future.

Acknowledgements. We are grateful to the Hellenic Ministry of National Education and Religious Affairs for the funding of this work through EPEAEK II. The work was part of the 'PYTHAGORAS I' project. We thank the reviewers for their constructive comments and suggestions.

\section{LITERATURE CITED}

Alexandresson H (1986) A homogeneity test applied to precipitation data. J Climatol 6:661-675

Arseni-Papadimitriou A, Maheras P, Patrikas I, Anagnostoupoulou C (2000) Distribution géographique des températures maximales par type de circulation et leurs tendances, en Grèce. Publ Assoc Int Climatol 13:347-355

Bartzokas A, Metaxas D (1991) Climatic fluctuation of temperature and air circulation in the Mediterranean. In: Duplessy JC, Pous A, Fantechi R (eds) Environment and quality of life, climate and global change. Proc Eur School of Clim Nat Hazard course, European Commission, Brussels, p 279-297

Bergant K, Kajfež-Bogataj L (2005) N-PLS regression as empirical downscaling tool in climate change studies. Theor Appl Climatol 81(1-2):11-23

Busuioc A, Deliang C, Hellstrom C (2001) Performance of statistical downscaling models in GCM validation and regional climate change estimates: application for Swedish precipitation. Int J Climatol 21:557-578

Corte-Real J, Zhang X, Wang X (1995) Large scale circulation regimes and surface climatic anomalies over the Mediterranean. Int J Climatol 15:1135-1150 
DeGaetano AT, Allen RJ (2002) Trends in twentieth-century temperature extremes across the United States. J Clim 15:3188-3205

Domonkos P, Kysely J, Riotrowicz K, Petrovic P, Likso T (2003) Variability of extreme temperature events in south-central Europe during the 20th century and its relationship with large scale circulation. Int J Climatol 23:987-1010

Feidas H, Makrogiannis T, Bora-Senta F (2004) Trend analysis of air temperature time series in Greece and their relationship with circulation using surface and satellite data: 1955-2001. Theor Appl Climatol 79:185-208

Folland CK, Miller C, Bader D, Crowe M and 6 others (1999) Workshop on indices and indicators for climate extremes (Asheville, NC, USA, 3-6 June 1997) - Breakout Group C: temperature indices for climate extremes. Clim Change 42:31-43

Giles BD, Flocas AA (1984) Air temperature variations in Greece. Part I. Persistence, trend and fluctuations. J Clim 4:531-539

Goodess CM, Jones PD (2002) Links between circulation and changes in the characteristics of Iberian Rainfall. Int J Climatol 22:1593-1615

Holton EB, Folland CK, Parker DE (2001) The changing incidence of extremes in worldwide and central England temperatures to the end of the twentieth century. Clim Change 50:267-295

IPCC (1996) Climate change 1995: the science of climate change. Contribution of Working Group I to the Second Assessment Report of the Intergovernmental Panel on Climate Change. Cambridge University Press, Cambridge

Jones PD, Holton EB, Folland CK, Hulme M, Parker DE, Basnett TA (1999) The use of indices to identify changes in climatic extremes. Clim Change 42:131-149

Jones R, Murphy J, Hassell D, Taylor R (2001) Ensemble mean changes in a simulation of the European climate of 2071-2100 using the new Hadley Centre regional modelling system HadAM3H/HadRM3H. Hadley Centre, Meteorological Office, Bracknell

Kalnay E, Kanamitsou M, Kistler R, Collins W and 18 others (1996) The NCEP/NCAR 40-year Reanalysis project. Bull Am Meteorol Soc 77:437-471

Klein-Tank AMG, Konnen GP (2003) Trends in indices of daily temperature and precipitation extremes in Europe, 1946-99. J Clim 16:3665-3680

Kutiel H, Maheras P (1998) Variations in the temperature regime across the Mediterranean during the last century and their relationship with circulation indices. Theor Appl Climatol 61:39-53

Kutiel H, Maheras P, Türkes M, Paz S (2002) North SeaCaspian Pattern (NCP) - an upper level atmospheric teleconnection affecting the eastern Mediterraneanimplication on regional climate. Theor Appl Climatol 72:173-192

Kysely J (2002) Temporal fluctuations in heat waves at Prague-Klementinum, the Czech Republic, from 1901-97,

Editorial responsibility: Otto Kinne, Oldendorf/Luhe, Germany and their relationships to atmospheric circulation. Int J Climatol 22:33-50

Maheras P, Kutiel H (1999) Spatial and temporal variations in the temperature regime in the Mediterranean and their relationship with circulation during the last century. Int J Climatol 19:745-764

Maheras P, Xoplaki E, Davies T, Martin-Vide J, Bariendos M, Alcoforado MJ (1999) Warm and cold monthly anomalies across the Mediterranean Basin and their relationship with circulation, 1980-1990. Int J Climatol 19:1697-1715

Maheras P, Patrikas I, Karacostas T, Anagnostopoulou C (2000a) Automatic classification of circulation types in Greece: methodology, description, frequency, variability and trend analysis. Theor Appl Climatol 67:205-223

Maheras P, Anagnostopoulou C, Patrikas I, Vafiadis M, Karacostas $\mathrm{T}(2000 \mathrm{~b})$ Simulation des pluies journalières en Grèce via une approche par types de circulation. Publ Assoc Int Climatol 14:181-188

Maheras P, Tolika K, Anagnostoupoulou C, Vafiadis M, Patrikas I, Flocas E (2004) On the relationships between circulation types and changes in rainfall variability in Greece. Int J Climatol 24:1695-1712

Makrogiannis TJ, Sahsamanoglou HS (1990) Time variation of mean sea level pressure over the major Mediterranean area. Theor Appl Climatol 41:149-156

Metaxas DA, Barzokas A, Vitsas A (1991) Temperature fluctuations in the Mediterranean during the last 120 years. Int J Climatol 11:897-908

Peterson TC, Vose R, Schmoyer R, Razuvaëv V (1998) Global historical climatology network (GHCN) quality control of monthly temperature data. Int J Climatol 18:1169-1179

Ryoo SB, Kwon WT, Jhun JG (2004) Characteristics of wintertime daily and extreme minimum temperature over South Korea. Int J Climatol 24:145-160

Sahsamanoglou HS, Makrogiannis TJ (1992) Temperature trends over the Mediterranean region, 1950-1998. Theor Appl Climatol 24:183-192

Sneyers R (1992) On the statistical analysis of series of observations. WMO Publ No. 415 (Tech Note No. 143). World Meteorological Organization, Geneva

Solman SA, Nunez MN (1999) Local estimates of global climate change: a statistical downscaling approach. Int J Climatol 19:835-861

Wilks DS (1995) Statistical methods in the atmospheric sciences: an introduction. Academic Press, San Diego, CA

Xoplaki E (2002) Climate variability over the Mediterranean. PhD Thesis, University of Bern

Xoplaki E, Gonzalez-Rouco JF, Luterbacher J, Wanner H (2003) Mediterranean summer air temperature variability and its connection to the large scale atmospheric circulation and SSTs. Clim Dyn 20:723-739

Yan Z, Jones PD, Davies TD, Moberg A and 11 others (2002) Trends of extreme temperatures in Europe and China based on daily observations. Clim Change 53:355-392

Submitted: May 10, 2005; Accepted: November 28, 2005

Proofs received from author(s): December 20, 2005 